\title{
S100A9 blockade improves the functional recovery after spinal cord injury via mediating neutrophil infiltration
}

\author{
FENG SUN $^{1,2}$, HAIWEI ZHANG ${ }^{3}$, TIANWEN HUANG ${ }^{2}$, JIANHUI SHI $^{4}$, TIANLI WEI ${ }^{1}$ and YANSONG WANG $^{1}$ \\ ${ }^{1}$ Department of Orthopedics, The First Affiliated Hospital of Harbin Medical University; Departments of ${ }^{2}$ Orthopedics and \\ ${ }^{3}$ Imaging, General Hospital of Heilongjiang General Administration of Agriculture and Reclamation; \\ ${ }^{4}$ Department of Orthopaedics, Heilongjiang Provincial Hospital, Harbin, Heilongjiang 150000, P.R. China
}

Received October 6, 2021; Accepted January 27, 2022

DOI: $10.3892 /$ etm.2022.11220

\begin{abstract}
Spinal cord injury (SCI) refers to damage to the spinal cord resulting from trauma, disease or degeneration. Controlling the inflammatory process and restoring neural homeostasis is hypothesized to prevent injury aggravation. S100 calcium-binding protein A9 (S100A9) is a pro-inflammatory alarm protein, which is expressed in and released by activated neutrophils. However, whether S100A9 could serve as an effective target for the treatment of SCI has not been reported to date. In the present study, a T10 spinal cord contusion injury model was established in Sprague-Dawley rats. S100A9 expression level was determined in the serum and injured spinal cord tissue via ELISA, reverse transcription-quantitative PCR (RT-qPCR) and western blotting. The S100A9-specific blocker, ABR-238901 (ABR), was administered during the inflammatory phase of SCI, as a form of treatment. Subsequently, the morphological structure, neuronal viability and inflammatory levels of injured spinal cord were observed by histopathology, immunohistochemistry and RT-qPCR. In the obtained results, S100A9 was found to be highly expressed in the injured spinal cord and serum in the first 3 days after SCI. However, at 28 days after surgery, ABR treatment significantly improved motor function, reduced the cavity formation and neutrophil infiltration in the lesion, which was verified via $H \& E$ staining and immunohistochemistry for myeloperoxidase. Furthermore, ABR treatment was found to effectively improve the survival and viability of neurons, as shown via Nissl staining and immunofluorescence of the synaptic plasticity markers, microtubule associated protein 2 and neurofilament 200 . Moreover, S100A9 blockade effectively upregulated the mRNA expression level of the anti-inflammatory genes, IL-4
\end{abstract}

Correspondence to: Dr Yansong Wang, Department of Orthopedics, The First Affiliated Hospital of Harbin Medical University, 23 Post Street Harbin, Heilongjiang 150000, P.R. China E-mail:wys1975@163.com

Key words: S100A9, neutrophils, inflammation, neurodegeneration, spinal cord injury and IL-10 and downregulated the mRNA expression level of the pro-inflammatory factors, IL- $1 \beta$, IL- 6 and TNF- $\alpha$. In addition, S100A9 blockade notably alleviated the apoptosis level of the injured nerve cells. Therefore, the findings of the present study revealed that S100A9 may be a useful target for the treatment of SCI.

\section{Introduction}

Spinal cord injury (SCI), which is characterized by motor and sensory dysfunction below the lesion level, refers to serious neurological damage resulting from trauma, disease or degeneration (1). According to the National SCI Statistical Center, there were $\sim 363,000$ SCI survivors living in the USA in 2019 and an additional 17,730 cases of SCI occur annually in the USA $(2,3)$. Progress has been made in the management and treatment of SCI; however, the contemporary medical technology (including surgical decompression, methylprednisolone, blood pressure augmentation, therapeutic hypothermia, cerebrospinal fluid drainage and rehabilitation training) still cannot achieve a satisfactory therapeutic effect (4).

The pathophysiology of SCI includes initial traumatic injury (primary injury) and subsequent progressive secondary injury involving ischemia, necrosis and infiltration by peripheral immune cells and cavity formation, resulting in the loss of spinal cord circuit connection (1). Due to the destruction of the blood-spinal cord barrier, neutrophils, monocytes and macrophages, as well as lymphocytes, infiltrate the site of injury, releasing a series of inflammatory factors and chemokines, and, activating the inflammatory response at the injury site (5). As reported previously, in an adult rat SCI model, the levels of inflammatory cytokines, such as TNF- $\alpha$, IL- 6 and IL-1 $\beta$, in the injured spinal cord tissue peaked at 6-12 $\mathrm{h}$ and continued to rise within 4 days after injury (6). Therefore, early anti-inflammatory intervention after injury could be expected to greatly benefit the management and treatment of patients with SCI in the future.

Pro-inflammatory alarm proteins, produced by activated leukocytes or dying cells, can emit tissue damage signals and trigger immune responses at the injury site (7). S100 calcium-binding protein A9 (S100A9), as a member of the pro-inflammatory alarm protein family, is mainly produced 
by and stored in large amounts in neutrophils. Moreover, S100A9 accounts for $\sim 40 \%$ of all cytoplasmic proteins of neutrophils (8). S100A9 can be rapidly released after stimulation, and mediates local immune response and endothelial cell injury by acting on the receptor for advanced glycation end product (RAGE) and toll like receptor 4 (TLR4), to promote the infiltration of peripheral immune cells into locally damaged tissues (8). S100A9 has been found to be significantly elevated in myocardial tissue and in the circulation in an acute myocardial infarction (MI) model (9). Furthermore, higher serum S100A9 levels in patients with acute coronary syndrome were shown to be associated with a significantly higher risk of heart failure (10). In addition, S100A9 was found to act as a key regulator of cardiomyocyte death in the early stages of MI/reperfusion (MI/R) and MI injury, while inhibition of S100A9 expression levels could effectively alleviate ventricular remodeling and cardiac function by blocking the neutrophil and macrophage infiltration post-MI/R and MI injury (9). However, the effects and mechanism of action of S100A9 in SCI remain unclear.

In the present study, the serum S100A9 level was detected in a rat SCI model. In addition, it was investigated whether inhibition of S100A9, using a specific blocker, could effectively promote axon viability, relieve apoptosis, reduce the inflammatory response and improve the microenvironment at the injured site. Furthermore, the mRNA and protein expression levels and mechanism of action of S100A9 were also examined. The aim was to determine whether S100A9 could be used as a biomarker and treatment target for patients with $\mathrm{SCI}$ in clinical practice in the future.

\section{Materials and methods}

Experimental animals. The study protocol was reviewed and approved by the Animal Care and Use Committee of the First Affiliated Hospital of Harbin Medical University (approval no. KY2020-105; Heilongjiang, China). All animal experiments were conducted in strict accordance with the guidelines for the Care and Use of Laboratory Animals of the National Institutes of Health of the United States. A total of 80 female Sprague-Dawley rats (age, 11-12 weeks; weight, 200-230 g) were purchased and raised in the Animal Experimental Center of the Second Affiliated Hospital of Harbin Medical University. All rats were placed in an isolated ventilation cage at $22-26^{\circ} \mathrm{C}$ and $50 \%$ relative humidity with a $12 / 12$-h light/dark cycle, and given free access to sterile granular food and water. All rats included in the study were allowed to acclimate for at least 7 days prior to the experiments.

SCI rat model and treatment. To establish the rat SCI model, the rats were anesthetized with an intraperitoneal injection of $1 \%(\mathrm{w} / \mathrm{v})$ sodium pentobarbital $(30 \mathrm{mg} / \mathrm{kg})$. The rats were placed in a prone position and dorsal laminectomy was performed at the level of the T10 vertebral body, followed by longitudinal incision of the dura to expose the spinal cord under a surgical microscope (SZX7; Olympus Corporation). The T10 spinal cord contusion model was constructed using an IH impactor precision striking device (Precision Systems and Instrumentation) according to a previous study (11). The equipment parameters were set as follows: The force was 400 kilodynes, the compression time was $5 \mathrm{sec}$ and the number of hits was 1. Contusion of the injured part, spasm of both lower limbs and spastic swing of the tail were considered to indicate successful establishment of the model (11). For the Sham group, the rats only underwent dorsal laminectomy without SCI. In order to investigate the effect of S100A9 blockade post-SCI, A100A9 specific inhibitor (ABR-238901; MedChemExpress) (12) was administered intraperitoneally, at 30 or $50 \mathrm{mg} / \mathrm{kg}$ (Low- and High-ABR groups, respectively), dissolved in DMSO, immediately following surgery, for 3 days. The same volume of DMSO was administered to the rats in the Vehicle group. After the procedure, the bladder of the rats was squeezed three times a day until spontaneous micturition was restored. At the same time, meloxicam $(4 \mathrm{mg} / \mathrm{kg})$ was injected subcutaneously for 3 days to relieve pain and penicillin $(1 \mathrm{ml}$; $160,000 \mathrm{U} / \mathrm{ml}$ ) was injected subcutaneously for 7 days to prevent infection.

Functional behavior test. The hindlimb motor function was compared among Sham, SCI, Vehicle, Low- and High-ABR groups preoperatively and at 1, 3, 7, 14, 21 and 28 days postoperatively using Basso-Beattie-Bresnahan (BBB) motor function scores according to a previous study (13). Briefly, the joint activity of the hindlimbs was scored as 0-7 points; the gait and the coordination of the hindlimbs were scored as 8-13 points; and the fine movements of the claws were scored as 14-21 points. The experiment was conducted by single-blind and multi-person independent evaluation. A total number of three observers participated in the scoring and the final score was obtained by calculating the mean value.

ELISA. Blood samples were collected from 5 rats in the Sham and SCI groups before and 3-, 6-, 12-, 24-, 48- and $72 \mathrm{~h}$ after surgery for ELISA detection. The rats were anesthetized with isoflurane (3\% for induction and $2 \%$ for maintenance), and blood samples were collected via the caudal vein at the predetermined time points after the surgery, followed by centrifugation at $1,000 \mathrm{x}$ for $20 \mathrm{~min}$ at $4^{\circ} \mathrm{C}$. The supernatant was carefully collected. The concentration of S100A9 before and 3, 6, 12, 24, 48 and $72 \mathrm{~h}$ after surgery, IL-1 $\beta 72 \mathrm{~h}$ after surgery, IL-6 $72 \mathrm{~h}$ after surgery, TNF- $\alpha 72 \mathrm{~h}$ after surgery, IL-4 $72 \mathrm{~h}$ after surgery and IL-10 $72 \mathrm{~h}$ after surgery among the different groups were detected using the rat S100A9 ELISA (cat. no. P2691; Wuhan Fine Biotech Co., Ltd.), rat IL-1 $\beta$ (cat. no. KE20005; ProteinTech Group, Inc.), rat IL-6 (cat. no. KET9004-96T; EliKine ${ }^{\mathrm{TM}}$ ), rat TNF- $\alpha$ (cat. no. KE20001; ProteinTech Group, Inc.), rat IL-4 (cat. no. KET9003-96T; EliKine $^{\mathrm{TM}}$ ), rat IL-10 (cat. no. KE20003; ProteinTech Group, Inc.) kits according to the manufacturer's instructions. In order to analyze the correlation between S100A9 and inflammatory/or anti-inflammatory factors, the S100A9 and IL-1 $\beta$, IL-6, TNF- $\alpha$, IL-4 and IL-10 levels at $72 \mathrm{~h}$ after surgery underwent Pearson's correlation analysis.

Tissue collection and preparation. At the predetermined time point, the rats were euthanized with $6 \%$ isoflurane for 3 min and death was confirmed by observing the heartbeat, breathing, pupils and nerve reflexes of the rats for $5 \mathrm{~min}$. Uncontrollable inflammatory response at the wound site was set as the humane endpoints (14). The thoracic cavity 
Table I. Primer sequences used in reverse transcription-quantitative PCR.

\begin{tabular}{lll}
\hline Gene & \multicolumn{1}{c}{ Forward primer $\left(5^{\prime}-3^{\prime}\right)$} & Reverse primer $\left(5^{\prime}-3^{\prime}\right)$ \\
\hline S100A9 & AACAGGATCTCAGCTGGAGC & TACTTCCCACAGCCTTTGCC \\
IL-1 $\beta$ & GCACAGTTCCCCAACTGGTA & GGAGACTGCCCATTCTCGAC \\
IL-6 & ACAAGTCCGGAGAGGAGACT & ACAGTGCATCATCGCTGTTC \\
TNF- $\alpha$ & GACCACGTAGCCGTGTTCAG & GGGCTCCACATTGCAGAGAA \\
IL-4 & CGTGATGTACCTCCGTGCTT & ATTCACGGTGCAGCTTCTCA \\
IL-10 & GAAGGACCAGCTGGACAACA & GGGGCATCACTTCTACCAGG \\
\end{tabular}

was quickly opened, followed by whole-body perfusion with normal saline. Then, the upper and lower $5 \mathrm{~mm}$ of the injured site were collected, rapidly frozen in liquid nitrogen and stored in $-80^{\circ} \mathrm{C}$ for subsequent experiments. For pathological examination, the rats were perfused with $4 \%$ paraformaldehyde after being perfused with normal saline until the limbs become stiff. Next, the upper and lower $5 \mathrm{~mm}$ of the injured site, as well as heart, liver, spleen, lung and kidney were placed in $4 \%$ paraformaldehyde for $24 \mathrm{~h}$ at $4^{\circ} \mathrm{C}$. Finally, xylene and gradient alcohol solution were used for dehydration of the paraffin-embedded tissues, while tissues embedded in optimum cutting temperature compound (Sakura Finetek USA, Inc.) were dehydrated in 10, 20 and $30 \%$ sucrose solutions. The embedded tissues were sectioned into $5-\mu \mathrm{m}$ slices and were placed in a pressure cooker with sodium citrate buffer $(0.01 \mathrm{~mol} / \mathrm{l} ; \mathrm{pH}, 6.0)$ for $20 \mathrm{~min}$ at $100^{\circ} \mathrm{C}$ for antigen retrieval (cat. no. AR0024; Wuhan Boster Biological Technology, Ltd.) for immunohistochemistry assay.

Reverse transcription-quantitative PCR (RT-qPCR). RT-qPCR was performed to determine the gene expressions of IL-1 $\beta$, IL-4, IL- 6 , IL-10 and TNF- $\alpha$. Briefly, total RNA from spinal cord tissues was harvested using TRIzol ${ }^{\circledR}$ reagent (Invitrogen; Thermo Fisher Scientific, Inc.) in accordance with the manufacturer's instructions and 2,000 ng RNA was reverse transcribed using PrimeScript ${ }^{\mathrm{TM}}$ RT Reagent Kit (Takara Bio, Inc.) according to the manufacturer's instructions. Finally, qPCR was performed using SYBR Green PCR Master Mix (Roche Diagnostics) with the following thermocycling conditions: Initial heat-activation at $95^{\circ} \mathrm{C}$ for $10 \mathrm{~min}$, followed by 45 cycles at $95^{\circ} \mathrm{C}$ for $15 \mathrm{sec}, 60^{\circ} \mathrm{C}$ for $30 \mathrm{sec}$ and $72^{\circ} \mathrm{C}$ for $30 \mathrm{sec}$. Each reaction was repeated three times. All primers used in the assay are summarized in Table I. GAPDH expression was used as the internal control. The gene expression levels relative to GAPDH were calculated using the $2^{-\Delta \Delta \mathrm{Cq}}$ method (15).

Western blot assay. RIPA lysis solution (Beyotime Institute of Biotechnology) and PMSF (Dalian Meilun Biology Technology Co., Ltd.), were used to lyse the collected tissues on ice for $30 \mathrm{~min}$, followed by centrifugation at $13,400 \mathrm{xg}$ for $20 \mathrm{~min}$ at $4^{\circ} \mathrm{C}$. The concentration of the total protein was examined using a BCA kit (Beyotime Institute of Biotechnology). Next, equal amount of protein $(80 \mu \mathrm{g})$ was loaded, separated by using $15 \%$ SDS-PAGE and subsequently transferred onto a PVDF membrane (Merck KGaA). After the membranes were blocked with $5 \%$ skimmed milk in $0.05 \%$ PBS-Tween 20 for $1 \mathrm{~h}$ at room temperature, they were incubated with primary antibodies against S100A9 (1:1,000; cat. no. 73425S; CST Biological Reagents Co., Ltd.), Bax (1:1,000; cat. no. 5023T; Cell Signaling Technology, Inc.), Bcl2 (1:5,000; cat. no. 60178-1-Ig; ProteinTech Group, Inc.), cleaved caspase-3 (1:1,000; cat. no. 9664T; Cell Signaling Technology, Inc.) and $\beta$-actin (1:1,000; cat. no. 4970s; Cell Signaling Technology, Inc.) overnight at $4^{\circ} \mathrm{C}$. HRP-conjugated secondary antibody (1:10,000; cat. no. 7074; Cell Signaling Technology, Inc.) was used to incubate the membranes for $1 \mathrm{~h}$ at the room temperature, followed by visualization with ECL reagent (Beyotime Institute of Biotechnology) via ChemiDoc MP System (Bio-Rad Laboratories, Inc.). Image-Pro Plus (version 6.0; Media Cybernetics, Inc.) was used for semi-quantitative analysis.

$H \& E$ staining. First, the 5- $\mu \mathrm{m}$ paraffin sections, prepared from spinal cord, heart, liver, spleen, lung and kidney fixed in $4 \%$ paraformaldehyde for $24 \mathrm{~h}$ at $4^{\circ} \mathrm{C}$, were heated at $60^{\circ} \mathrm{C}$ for $30 \mathrm{~min}$ and washed in xylene I and II, for $5 \mathrm{~min}$ each time. Next, the sections were placed in 100,100, 95, 95 and $80 \%$ gradient ethanol solutions for $5 \mathrm{~min}$ each time, and were washed twice with steamed water. The sections were stained with hematoxylin for $1 \mathrm{~min}$ at room temperature, then washed twice with distilled water. After being differentiated in $1 \%$ hydrochloric acid and washed in distilled water, the sections were stained with eosin (Beijing Solarbio Science \& Technology Co., Ltd.) for $2 \mathrm{~min}$ at room temperature and observed under a light microscope (Leica Microsystems GmbH).

Cavity volume calculation. The cavity volume calculation was based on the H\&E sections and was determined using Image-Pro Plus (version 6.0), as described in a previous study (16). Firstly, the diameters from three levels (at the epicenter of the lesion, $0.5 \mathrm{~cm}$ rostral to the epicenter and $0.5 \mathrm{~cm}$ caudal to the epicenter) were used to acquire the average diameter of the spinal cord at the lesion site. Subsequently, the area of the cross-section of the spinal cord at the lesion site was calculated using the average diameters. Finally, the volume was obtained by multiplying the cross-section by $1 \mathrm{~cm}$ (the length of the spinal cord). The cavity volume was divided 
by the volume of the spinal cord at the lesion site to obtain relative cavity volume $(\%)$.

Nissl staining. After dehydrating as aforementioned for H\&E staining, the sections were stained with $1 \%$ cresyl violet for $30 \mathrm{~min}$ at room temperature, and dehydrated using an ascending alcohol series (70, 95 and 100\%) for $5 \mathrm{~min}$ each time. Images were captured under a light microscope (Leica Microsystems $\mathrm{GmbH}$ ). Image-Pro Plus (version 6.0) was used for semi-quantitative analysis.

Immunofluorescence. Frozen 5- $\mu \mathrm{m}$ sections were prepared from spinal cord fixed in $4 \%$ paraformaldehyde for $24 \mathrm{~h}$ at $4^{\circ} \mathrm{C}$ and were placed in $0.1 \mathrm{M}$ TBS for $10 \mathrm{~min}$ at room temperature followed by incubation in $0.3 \% \mathrm{H}_{2} \mathrm{O}_{2}$ for $30 \mathrm{~min}$ at room temperature. Next, $0.1 \%$ Triton $\mathrm{X}-100$ was utilized to permeabilize the sections for $30 \mathrm{~min}$ at room temperature. After blocking with 10\% normal goat serum (Beijing Zhongshan Jinqiao Biotechnology Co., Ltd.) for $30 \mathrm{~min}$ at room temperature, the tissue sections were incubated overnight at $4^{\circ} \mathrm{C}$ with primary antibodies against microtubule associated protein 2 (1:20; cat. no. ab254143) and neurofilament 200 (1:100; cat. no. ab134306) (both from Abcam). Following which, the primary antibody was removed and the cells were incubated with the secondary antibody (1:500; cat. no. ab150113; Abcam) for $1 \mathrm{~h}$ at room temperature. After staining the cell nuclei with DAPI (Beijing Solarbio Science \& Technology Co., Ltd.) for $5 \mathrm{~min}$ at room temperature, images were captured using a fluorescence microscope (Olympus Corporation). Image-Pro Plus (version 6.0) was used for semi-quantitative analysis.

Immunohistochemistry. The 5- $\mu \mathrm{m}$ paraffin-embedded sections, prepared from spinal cord fixed in $4 \%$ paraformaldehyde for $24 \mathrm{~h}$ at $4^{\circ} \mathrm{C}$, were placed in a pressure cooker with sodium citrate buffer $(0.01 \mathrm{~mol} / \mathrm{l} ; \mathrm{pH}, 6.0)$ for $20 \mathrm{~min}$ at $100^{\circ} \mathrm{C}$ for antigen recovery (Wuhan Boster Biological Technology, Ltd.). The activity of endogenous peroxidase was blocked by $3 \% \mathrm{H}_{2} \mathrm{O}_{2}$ at room temperature for $20 \mathrm{~min}$, followed by blocking with $10 \%$ goat serum (Beijing Zhongshan Jinqiao Biotechnology Co., Ltd.) for $30 \mathrm{~min}$ at room temperature. Primary antibody against myeloperoxidase (1:1,000; cat. no. 14569; Cell Signaling Technology, Inc.) was utilized to incubate the sections overnight at $4^{\circ} \mathrm{C}$ and HRP-conjugated secondary antibody (1:1,000; cat. no. ab6721; Abcam) was used to incubate the sections for $1 \mathrm{~h}$ at room temperature. After washing with PBS-0.05\% Tween-20, DAB (Zhongshan Jinqiao Biotechnology Co., Ltd. China) was used for visualization. Hematoxylin was utilized for nuclei counterstaining at room temperature for $3 \mathrm{~min}$. Finally, images were captured under a light microscope (Leica Microsystems $\mathrm{GmbH}$ ).

Statistical analysis. In the present study, all the statistical analyses were performed with SPSS 20.0.0 software (IBM Corp.) and results are presented as mean \pm SD $(n=5)$. An unpaired Student's t-test was conducted to determine the differences between the two groups, while differences among multiple groups were analyzed using one-way ANOVA followed by Tukey's multiple comparisons test. A two-way repeated-measures ANOVA followed by the Sidak multiple comparisons test was used for the BBB motor function evaluation. $\mathrm{P}<0.05$ was considered to indicate a statistically significant difference.

\section{Results}

S100A9 expression is upregulated in spinal cord tissue and plasma following SCI. First, in order to investigate the expression status of S100A9 in spinal cord tissue following SCI, spinal cord tissue before and after surgery was collected to determine the gene and protein expression levels of S100A9. There was no significant change in the mRNA expression levels of S100A9 in the Sham group, while the expression level of S100A9 in the SCI group was the highest at $6 \mathrm{~h}$ post-surgery (post-SUR) and then exhibited a decreasing trend. In addition, the expression levels in the SCI group were higher compared with that in the Sham group $72 \mathrm{~h}$ post-SUR (Fig. 1A). Similarly, the protein expression levels of S100A9 were consistent with those of the mRNA expression levels; S100A9 expression levels increased to the maximum at $6 \mathrm{~h}$ post-SUR followed by a gradual downward trend, whereas there were no significant changes in the Sham group (Fig. 1B). Since S100A9 is mainly produced by and stored in neutrophils, it was hypothesized that tissue injury could activate neutrophils to release S100A9. Therefore, the concentration of S100A9 in the serum of both groups was detected. It was found that the concentration level of S100A9 was the highest at $6 \mathrm{~h}$ post-SUR in the SCI group, then decreased gradually. Compared with that in the SCI group, the concentration of S100A9 changed slightly in the Sham group, which may be attributed to the soft tissue injury caused by surgery (Fig. 1C).

Notably, excessive expression of S100A9 has been observed in several inflammatory diseases, such as sepsis, myocardial infraction and chronic obstructive pulmonary disease $(10,17,18)$. As aforementioned, S100A9 expression was elevated to the maximum at $6 \mathrm{~h}$ after SCI, followed by a gradual downward trend of S100A9 expression. In order to investigate whether there was a correlation between S100A9 when its expression decreased and inflammatory/anti-inflammatory factor levels, correlation analysis between the concentrations of S100A9 and inflammatory (IL-1 $\beta$, IL-6 and TNF- $\alpha$ ) and anti-inflammatory factors (IL-4 and IL-10) in the plasma was analyzed $72 \mathrm{~h}$ after surgery was performed. The results revealed that S100A9 was positively correlated with IL-1 $\beta$ ( $\mathrm{r}=0.95)$, IL-6 $(\mathrm{r}=0.90)$ and TNF- $\alpha$ $(\mathrm{r}=0.90)$, while was negatively correlated with IL-4 $(\mathrm{r}=-0.89)$ and IL-10 ( $r=-0.91)$ (Fig. 1D). These results demonstrated that S100A9 was highly expressed in both spinal cord tissue and plasma after SCI, and reached its peak $6 \mathrm{~h}$ after injury. Moreover, the concentration of S100A9 was positively correlated with pro-inflammatory and negatively correlated with anti-inflammatory factors.

S100A9 blockade improves motor function after SCI. In order to investigate whether inhibition of S100A9 expression exerted therapeutic effects in a SCI rat model, H\&E staining and BBB score evaluation were conducted 28 days post-SUR. In the SCI group, there was significant tissue loss in both the rostral and caudal segments of the injured spinal cord, accompanied 
A
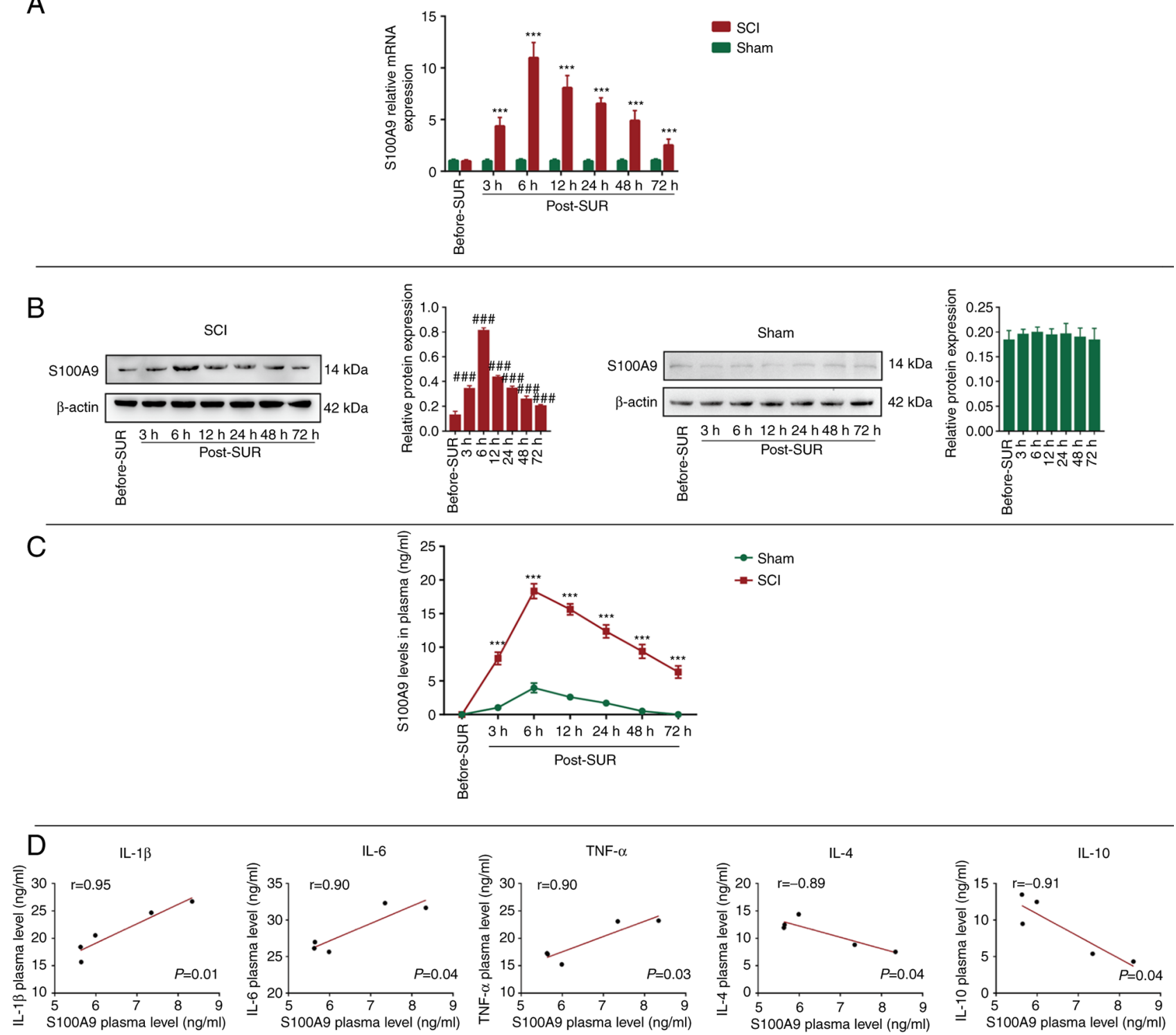

Figure 1. S100A9 expression in the spinal cord tissue and serum following SCI. S100A9 (A) mRNA and (B) protein expression level, and (C) concentration in the spinal cord tissue and serum from the SCI and Sham groups pre-OR and at 3, 6, 12, 24, 48 and $72 \mathrm{~h}$ post-OR, respectively. (D) Correlation analysis between S100A9 and IL-1 $\beta$, IL-6, TNF- $\alpha$, IL-4 and IL-10 concentration using Pearson's correlation analysis. Data are presented as the mean \pm SD. $n=5$. ${ }^{* * *} \mathrm{P}<0.001$ vs. Sham group; ${ }^{\# \# \#} \mathrm{P}<0.001$ vs. Before-SUR group. S100A9, S100 calcium-binding protein A9; SCI, spinal cord injury; pre-OR, before the operation; post-OR, after the operation.

by infiltration by a large number of inflammatory cells and vacuolization. However, treatment with the S100A9-specific blocker, ABR-238901 (ABR), was associated with significantly less tissue defects, less inflammatory cell infiltration and alleviation of vacuolization. In addition, compared with that in the low-dose group (Low-ABR), the high-dose group (High-ABR) exhibited more notable therapeutic and anti-injury effects (Fig. 2A). In addition, the cavity volume was significantly reduced in both ABR groups compared with that in the SCI group. Specifically, the cavity volume in the High-ABR group was significantly smaller than that in the Low-ABR group (Fig. 2B). More importantly, compared with that in the SCI group, blocking the expression of S100A9 could effectively improve the motor function in rats in the $A B R$ group. As expected, the BBB scores in the High-ABR group were significantly higher compared with that in the Low-ABR group (Fig. 2C). These results suggested that blocking S100A9 may reduce the cavity volume and improve motor function after SCI in a dose-dependent manner.

S100A9 blockade improves neuronal cell survival. MAP2 is a marker of mature neurons. In the present study, the expression level of MAP2 was found to be significantly decreased in the lesion area of the SCI group; however, it was increased in both ARB treated groups with that of High-ARB to show higher MAP2 expression level that of Low-ARB group (Fig. 3A). The molecular marker, NF200 is one of the main components of the neuronal cytoskeleton, which provides structural support for axons (16). It was observed that S100A9 blockade could effectively promote the expression of NF200 at the lesion area in comparison with the SCI group and High-ARB could improve the expression of NF200 compared with that in the 
A

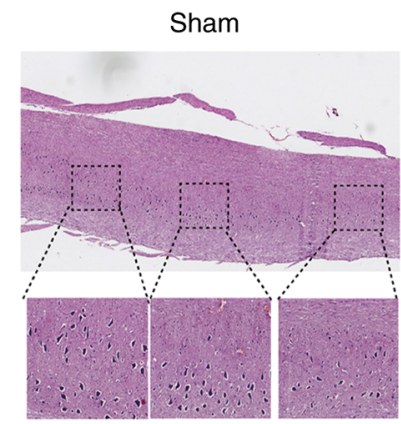

High-ABR

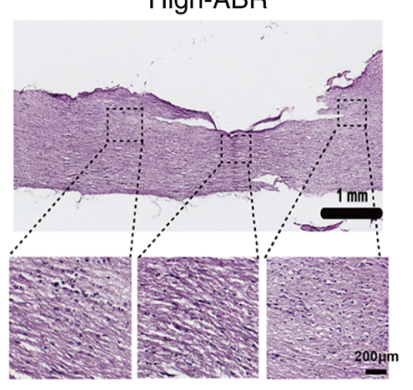

$\mathrm{SCl}$

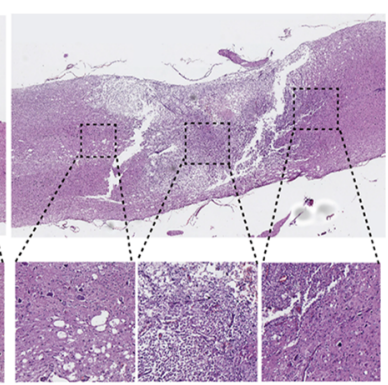

B

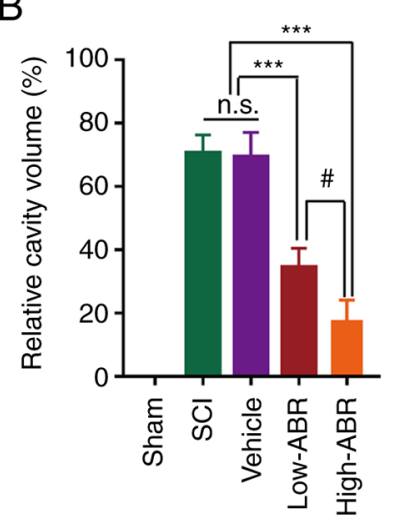

Vehicle

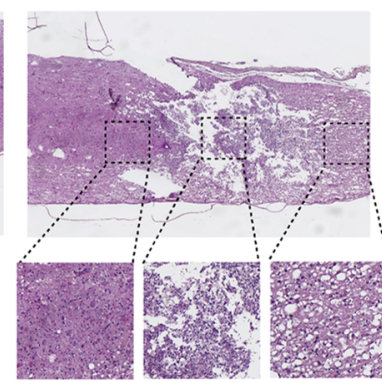

C

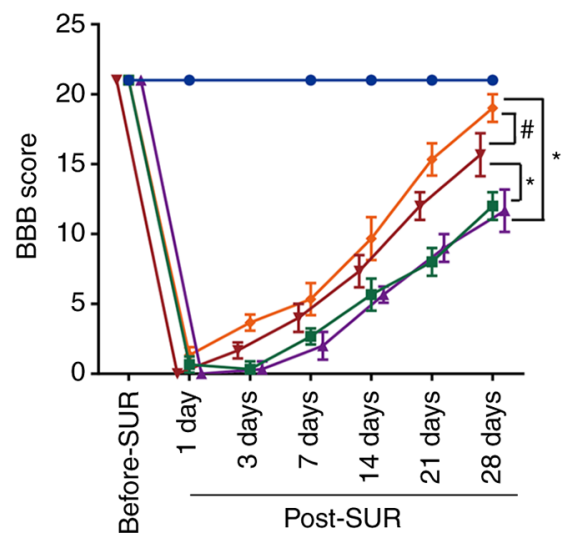

Low-ABR

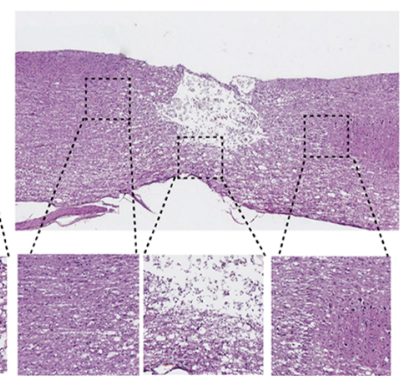

Figure 2. S100A9 blockade improves the recovery of the injured cord after SCI. (A) H\&E staining for histological analysis 28 days post-OR among the different experimental groups. Scale bar, $1 \mathrm{~mm}$ (upper panel) and $200 \mu \mathrm{m}$ (lower panel). (B) Relative cavity sizes were calculated by dividing the cavity volume by the spinal cord volume at the lesion site in the vertical direction. (C) BBB score evaluation for motor function after SCI among the different experimental groups. Data are presented as the mean $\pm \mathrm{SD} . \mathrm{n}=5 .{ }^{*} \mathrm{P}<0.05,{ }^{* * *} \mathrm{P}<0.001 .{ }^{*} \mathrm{P}<0.05$. S100A9, S100 calcium-binding protein A9; SCI, spinal cord injury; post-OR, after the operation; BBB, Basso-Beattie-Bresnahan; High-ABR, high ABR dose; Low-ABR, low ABR dose; n.s., not significant.

Low-ABR (Fig. 3B). Similarly, Nissl bodies were dissolved and disappeared in the SCI group; however, the number of Nissl bodies in the ARB groups were markedly higher compared with that in the SCI group. Nissl bodies were higher in High-ARB group as compared with that in the Low-ARB group (Fig. 3C). These results suggested that S100A9 blockade may contribute to the survival of neurons and higher does ABR would improve the survival of neurons after SCI.

S100A9 blockade relieves inflammation and apoptosis after SCI. Compared with that in the SCI group, S100A9 blockade could inhibit the expression of MPO in the lesion area. MPO expression was notably lower in High-ARB group than that in Low-ARB group, suggesting S100A9 blockade might inhibit infiltration by neutrophils (Fig. 4A). Excessive inflammation can aggravate the damage of neurons after SCI; therefore, limiting pro-inflammatory damage could improve SCI outcome (19-21) Therefore, the expression levels of pro-inflammatory and reparatory genes were also examined. As shown in Fig. 4B, compared with in the SCI group, application of the S100A9 inhibitor in the Low- or High-ABR groups significantly reduced the expression levels of pro-inflammatory genes (IL- $1 \beta$, IL- 6 and TNF- $\alpha$ ) and significantly promoted the expression levels of anti-inflammatory genes (IL-4 and IL-10). In addition, compared with that in the Low-ABR group, there were notable anti-inflammatory effects in the High-ABR group. Furthermore, S100A9 blockade notably increased the expression levels of the anti-apoptotic protein, $\mathrm{Bcl} 2$ and effectively inhibited the expression level of the pro-apoptotic proteins, Bax and cleaved caspase-3. Anti-apoptosis effect was notably higher in the High-ABR group compared with that in the Low-ABR group (Fig. 4C). These results suggested that S100A9 blockade may relieve inflammation and apoptosis after SCI. Finally, H\&E staining showed that compared with that in the Sham group, no notable tissue and structural damage was found in the other groups, verifying that blocking S100A9 expression did not cause pathological damage to functional organs, such as heart, liver, spleen, lung or kidney (Fig. 5).

\section{Discussion}

SCI refers to devastating neurological damage to the spinal cord resulting from trauma, disease or degeneration, which can have a detrimental impact on motor function and the quality of life of those affected. There is no radical or effective treatment for SCI, and the majority of the treatments are symptomatic $(1,22)$. Therefore, there is an urgent requirement to further elucidate the pathological mechanism of SCI in order to design treatment methods to curb or even reverse the progression of SCI in the future. In the present study, S100A9 mRNA and protein expression level was increased in the acute phase of SCI. The application of a S100A9-specific inhibitor in the early stage of SCI was shown to effectively alleviate infiltration by neutrophils and the inflammatory response, inhibit the apoptosis of neurons and promote the recovery of motor 
A
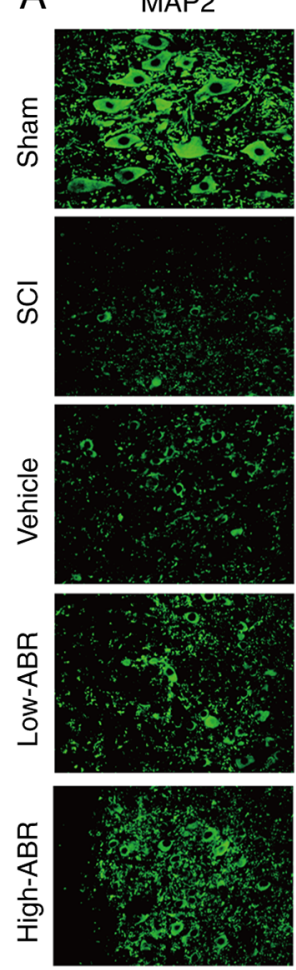

DAPI
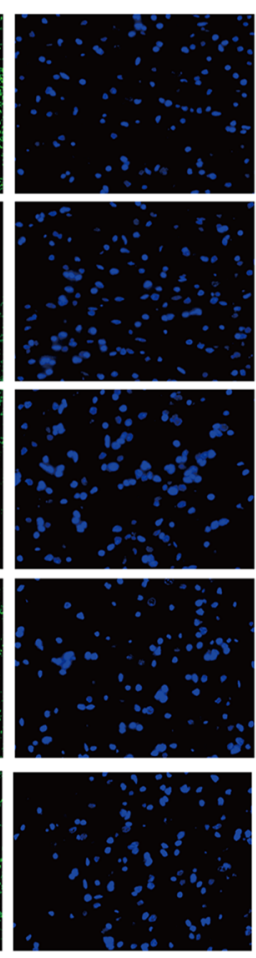

Merged
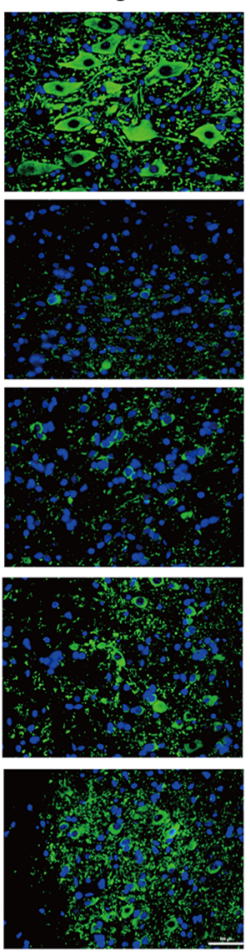

B
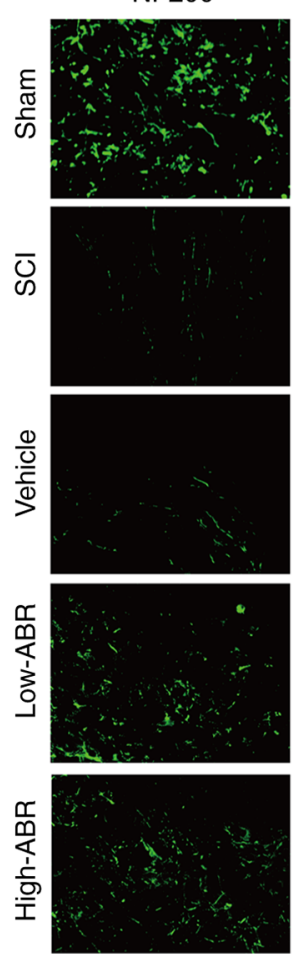

DAPI
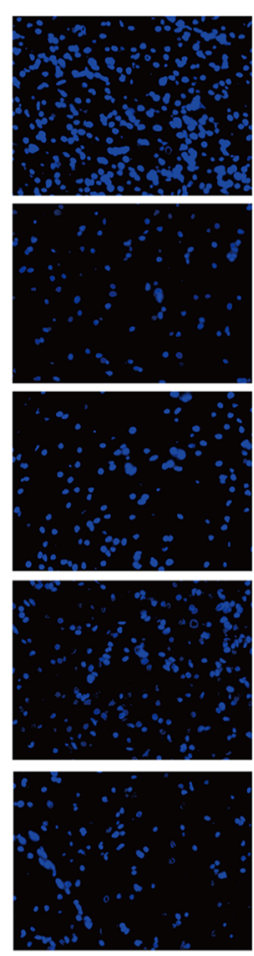

Merged
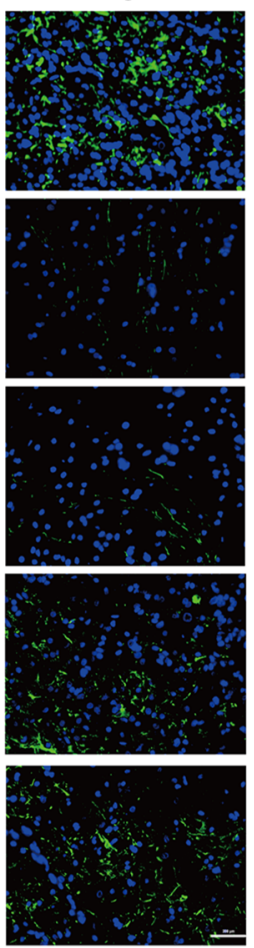

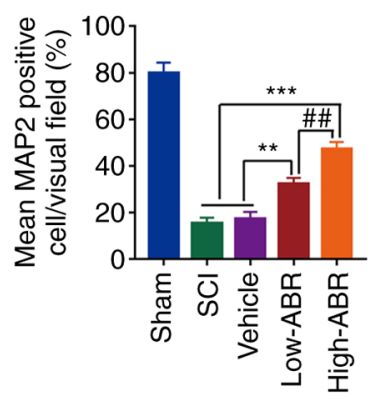

C

$\mathrm{sCl}$ Vehicle
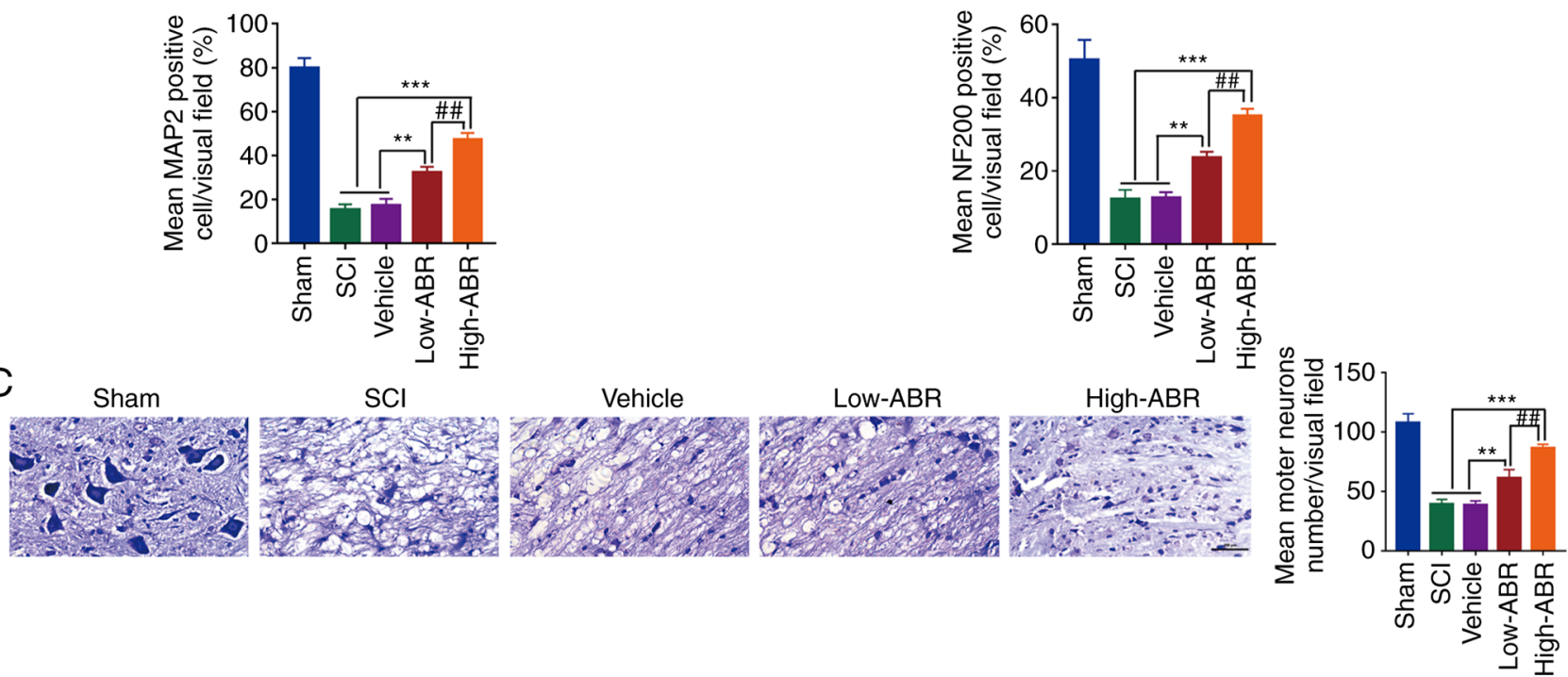

Figure 3. S100A9 blockade improves neuronal cell survival after SCI. Immunofluorescence of (A) MAP2 and (B) NF200 at the lesion site on day 28 following surgery among the different experimental groups. (C) Nissl staining for neuronal morphology at the lesion site 28 days post-OR among groups. $\mathrm{n}=5$. Scale bar, $200 \mu \mathrm{m} .{ }^{* *} \mathrm{P}<0.01,{ }^{* * *} \mathrm{P}<0.001 .{ }^{\# \#} \mathrm{P}<0.01$. S100A9, S100 calcium-binding protein A9; SCI, spinal cord injury; MAP2, microtubule associated protein 2; NF200, neurofilament 200; post-OR, after the operation; High-ABR, high ABR dose; Low-ABR, low ABR dose.

function. Therefore, S100A9 may be an effective therapeutic target for SCI in future clinical practice.

After the initial mechanical SCI, there is not only typical secondary injury, but also long-term progressive neurodegeneration. As reported in a subgroup of patients with traumatic SCI, neurological function continued to deteriorate even $>6$ months after the injury $(23,24)$. In addition, evidence from animal experimental studies also revealed that limiting pro-inflammatory damage can improve the outcome and prognosis of SCI (19-21). It has been previously indicated that neutrophils constitute the first immune cell group to be activated after SCI and accumulate rapidly within the lesion core in areas of hemorrhagic transformation and subsequent hemorrhagic necrosis within the first $72 \mathrm{~h}$ (25). Generally, neutrophil infiltration often leads to cascade tissue damage, which is due to the excessive release of cytokines, chemokines and prostaglandins, the ensuing oxidative damage, and, the release of toxic granules $(26,27)$. Therefore, effectively preventing neutrophil infiltration and the resulting inflammatory injury may limit the extent of the injury to the spinal cord tissue and the necrosis or apoptosis of neurons in the initial stage of SCI, which would be beneficial for SCI treatment. 
A

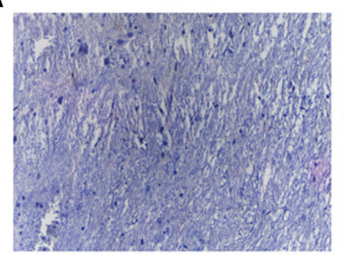

B

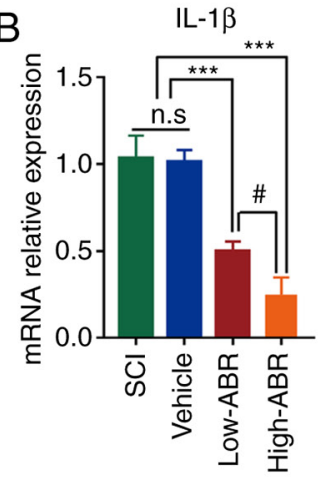

SCI

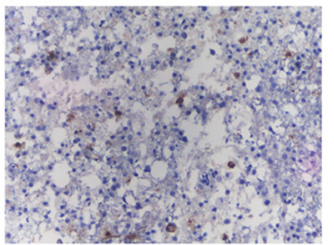

IL-6

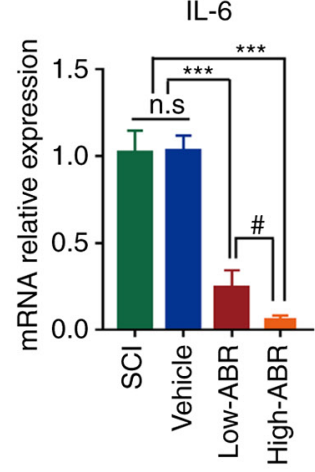

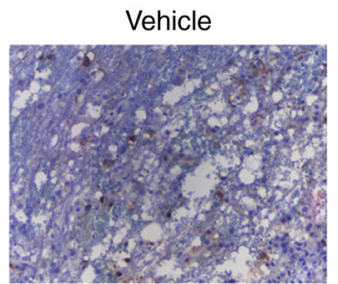
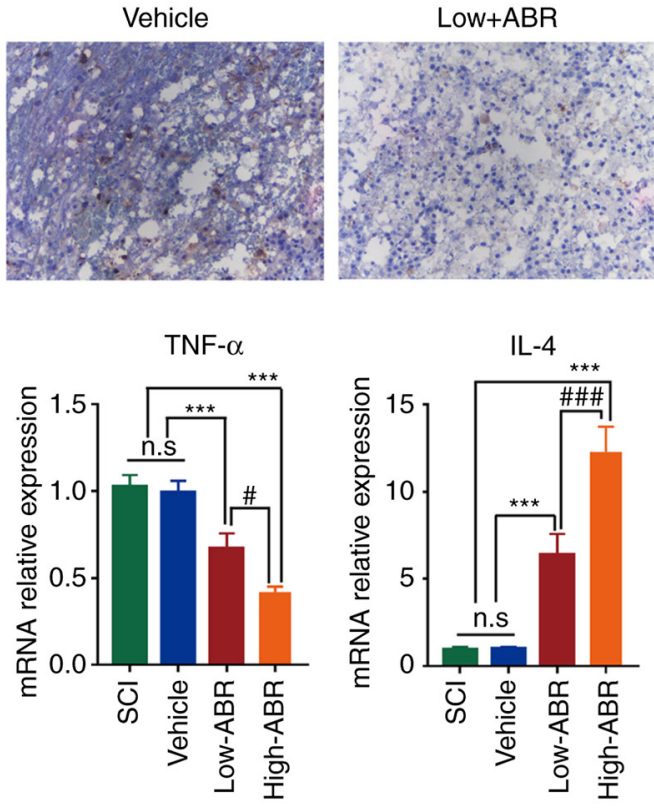

High+ABR
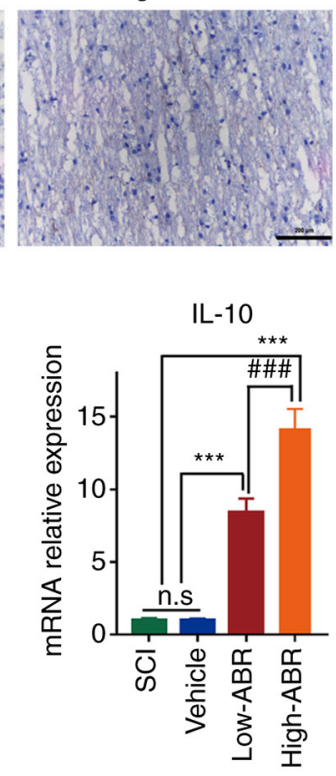

C
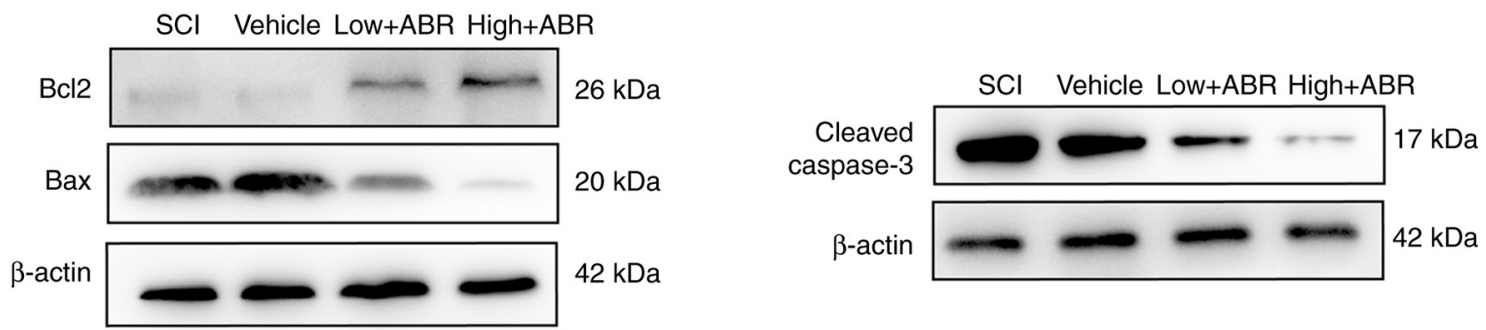

Figure 4. S100A9 blockade relieves inflammation and apoptosis after SCI. (A) Immunohistochemistry for MPO at the lesion site 28 days post-OR among groups. (B) mRNA expression level of pro-inflammatory genes (IL-1 $\beta$, IL-6 and TNF- $\alpha$ ) and anti-inflammatory genes (IL-4 and IL-10) at the injury site 28 days post-OR among the groups. (C) Protein expression level of $\mathrm{Bcl} 2$, Bax and cleaved caspase-3 at the injury site 28 days post-OR among the groups. $\mathrm{n}=5$. ${ }^{* * * *} \mathrm{P}<0.001 .{ }^{\#} \mathrm{P}<0.05,{ }^{\# \#} \mathrm{P}<0.001$. Scale bar, $200 \mu \mathrm{m}$. S100A9, S100 calcium-binding protein A9; SCI, spinal cord injury; MPO, myeloperoxidase; post-OR, after the operation; High-ABR, high ABR dose; Low-ABR, low ABR dose; n.s, not significant.

The alarmin S100A9, also referred to as calprotectin, is abundantly stored in neutrophils and is rapidly released in response to inflammatory stimuli to serve as a damage-associated molecular pattern. Neutrophils are the most important source of extracellular S100A9 $(28,29)$. It was recently demonstrated that S100A9 is the most significantly upregulated gene and the first responder (first 3 days after tissue injury) and peaked at $6 \mathrm{~h}$ in myocardial tissue after ischemia, which shown that S100A9 exerted its biological role in the first 3 days after injury. The acute release of S100A9 has been associated with the development of heart failure in patients with acute coronary syndrome (10). Administration of a specific S100A9 blocker can effectively reduce the numbers of neutrophils and monocytes/macrophages in the myocardium and improve the recovery of cardiac function after MI (30); the specific molecular mechanism is that S100A9 inhibits NDUFS gene expression via TLR4-mediated peroxisome proliferator-activated receptor- $\gamma$ coactivator $1 /$ nuclear respiratory factor 1 signaling, which in turn inhibits mitochondrial complex I, leading to inflammation and injury of tissues and cells (9). Moreover, in autoimmune diseases, inhibiting the expression of S100A9 could also effectively restrict the sterile inflammation via a TLR4-related mechanism (31). These previous results suggest that S100A9 may be an effective therapeutic target in certain inflammatory diseases.

Generally, SCI treatment aims to improve neuronal viability and survival, maintain a favorable microenvironment, inhibit inflammatory response, and promote the secretion of certain neurotrophic factors to facilitate spinal cord repair (32). In the present study, S100A9 was found to be significantly overexpressed in the plasma and spinal cord tissue in the first 3 days in a rat SCI model, while its expression peaked $6 \mathrm{~h}$ after injury. However, there was no significant change in the spinal cord tissue from the Sham group. At the same time, the plasma changes of S100A9 in the SCI and Sham group had a similar trend; however, the trend in the Sham group might be due to surgery. In addition, the concentration of S100A9 in Sham group is also significantly lower than that in SCI group. The aforementioned results are consistent with the expression level of S100A9 in myocardial tissue and plasma of ischemic heart disease $(9,10)$, which may be due to SCI and myocardial ischemia-reperfusion having the same pathological basis: Inflammatory injury. More importantly, S100A9 concentration in plasma was positively correlated with the pro-inflammatory cytokines (IL-1 $\beta$, IL- 6 and TNF- $\alpha$ ), while was negatively correlated with the anti-inflammatory factors (IL-4 and IL-10). Therefore, 

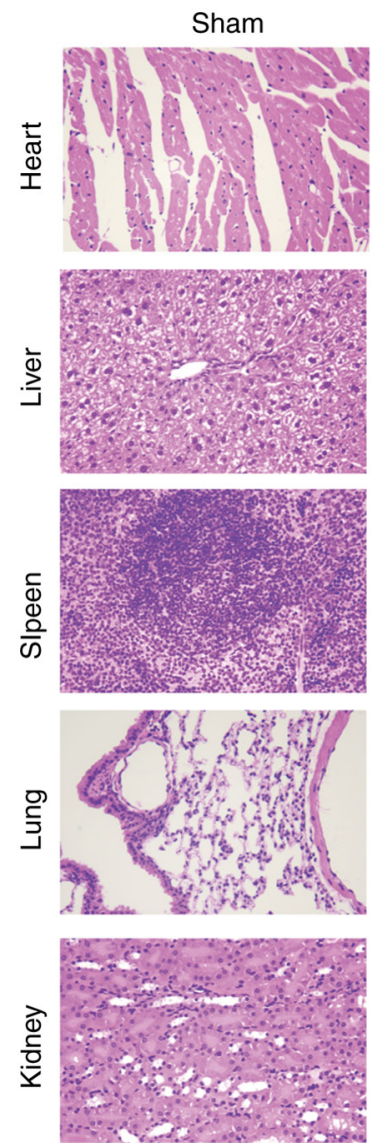
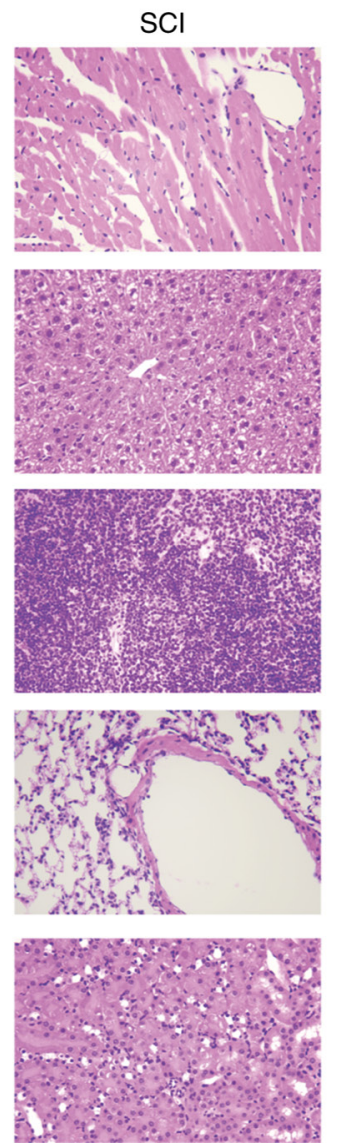
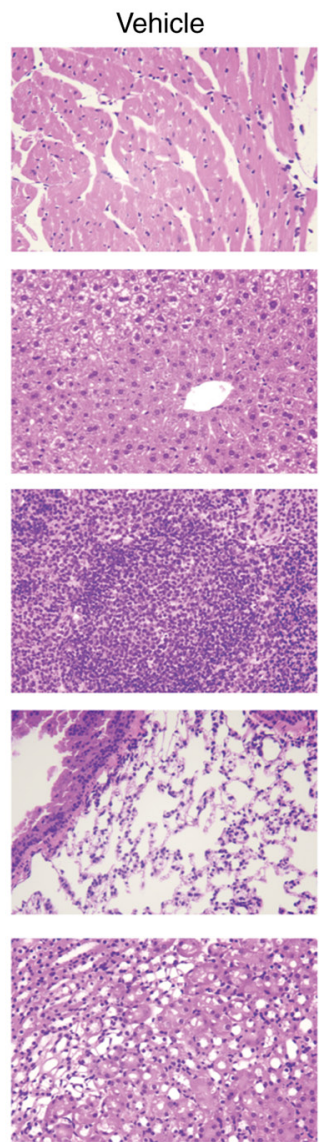
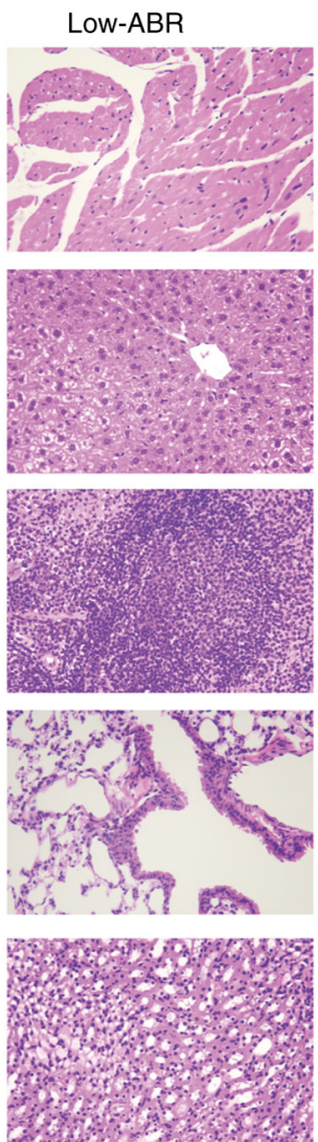
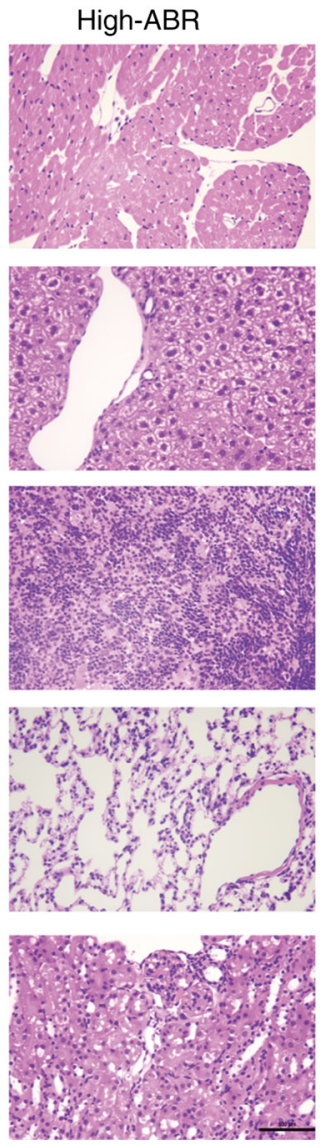

Figure 5. H\&E staining was used to detect possible pathological damage caused by S100A9 in tissues and organs. Scale bar, 500 $\mu$ m. S100A9, S100 calcium-binding protein A9; SCI, spinal cord injury; High-ABR, high ABR dose; Low-ABR, low ABR dose.

clinically, for patients with SCI combined with no other inflammatory diseases, S100A9 expression in the plasma may be associated with inflammatory process and may serve as a reliable detection index to judge the severity of injury and assist in the decision-making of clinical treatment.

The specific inhibitor of S100A9, ABR-238901, can inhibit S100A9 expression in the peripheral circulation system and injured tissues. Low levels of S100A9 expression do not only inhibit the cytotoxic effects of neutrophils, but can also reduce the effect on TLR4 and RAGE, thus reducing the functional damage to tissue cells $(10,24,30)$. In the present study, the application of ABR-238901, whether at low $(30 \mathrm{mg} / \mathrm{kg})$ or high doses $(50 \mathrm{mg} / \mathrm{kg})$, could both effectively reduce the infiltration by neutrophils and the cavity volume in the spinal cord tissue after SCI, as demonstrated via histopathological analysis. The survival and viability of neurons following S100A9 blockade were mainly verified by examining the expression levels of MAP2 and NF200, which are present in axons and dendrites, respectively (33). As expected, S100A9 blockade significantly elevated the expression of MAP2 and NF200, suggesting that S100A9 blockade promoted the survival and viability of neurons after SCI. Moreover, S100A9 blockade significantly inhibited the mRNA expression level of pro-inflammatory genes (IL-1 $\beta$, IL- 6 and TNF- $\alpha$ ) and promoted the mRNA expression level of anti-inflammatory genes (IL-4 and IL-10). Low levels of inflammation is expected to further reduce the recruitment of chemicals (such as CXCL1/CXCL2) and the infiltration of neutrophils in the injury site (34). S100A9 blockade also showed similar results in the regulation of apoptosis-related proteins (inhibited the expression of pro-apoptotic proteins and promoted the expression of anti-apoptotic proteins). Moreover, compared with that in the low dose of ABR-238901 group, a high dose of ABR-238901 could effectively reduce the cavity volume, improve the BBB score of motor function and promote the survival ability of neurons after injury. At the same time, a high dose of ABR-238901 also significantly inhibited the inflammatory process and apoptosis level in comparison with the low dose group, as well as infiltration of neutrophils, which was verified by MPO expression in the lesion site. Finally, ABR-238901 treatment did not cause notable pathological damage to the heart, liver, spleen, lung or kidney, indicating that ABR-238901 treatment was safe and effective in the SCI rat model and may be useful in the treatment of SCI.

Nevertheless, the present study also has some limitations. Only female rats were utilized. If both sexes were used, it would enable more rigorous and reliable research conclusions. In addition, the tissue infiltration of S100A9 to neutrophils was indirectly verified using MPO expression. If the rat peripheral blood cell subtypes could be counted and analyzed, the experimental results would be more convincing.

In conclusion, during the pathological process of SCI, S100A9 expression is significantly upregulated in both the plasma and spinal cord tissue. Inhibition of S100A9 using specific inhibitors can significantly suppress neutrophil 
infiltration, relieve the inflammatory response and improve the viability and survival rate of neurons, which is conducive to the recovery of motor function after SCI. Therefore, with the development and maturity of targeted drugs, nano systems and tissue engineering technology, targeted drug delivery of more efficient technology is expected to be popularized in clinical work in the future.

\section{Acknowledgements}

Not applicable.

\section{Funding}

This study has been financially supported by the National Natural Science Foundation of China (grant no. 81871781).

\section{Availability of data and materials}

The datasets used and/or analyzed during the current study are available from the corresponding author on reasonable request.

\section{Authors' contributions}

YW, FS and TW substantially contributed to the conception and the design of the study. HZ, TH and JS contributed to data acquisition and statistical analysis. FS and TW were responsible for interpretation of experimental data, manuscript writing, and reviewing and revision of the manuscript. YW and FS confirmed the authenticity of all the raw data. All authors read and approved the final version of the manuscript.

\section{Ethics approval and consent to participate}

The study was approved by the Ethics Committee of The First Affiliated Hospital of Harbin Medical University (Heilongjiang, China).

\section{Patient consent for publication}

Not applicable.

\section{Competing interests}

The authors declare that they have no competing interests.

\section{References}

1. Hutson TH and Di Giovanni S: The translational landscape in spinal cord injury: Focus on neuroplasticity and regeneration Nat Rev Neurol 15: 732-745, 2019.

2. Dwyer-Lindgren L, Bertozzi-Villa A, Stubbs RW, Morozoff C, Kutz MJ,Huynh C, Barber RM, Shackelford KA, Mackenbach JP, van Lenthe FJ, et al: US county-level trends in mortality rates for major causes of death, 1980-2014. JAMA 316: 2385-2401, 2016.

3. National SCI Statistical Center: Facts and figures at a glance. University of Alabama at Birmingham, AL, USA, 2019.

4. Ahuja CS, Nori S, Tetreault L, Wilson J, Kwon B, Harrop J, Choi D and Fehlings MG: Traumatic spinal cord injury-repair and regeneration. Neurosurgery 80 (Suppl 3): S9-S22, 2017.

5. Jones TB: Lymphocytes and autoimmunity after spinal cord injury. Exp Neurol 258: 78-90, 2014
6. Nakamura M, Houghtling RA, Macarthur L, Bayer BM and Bregman BS: Differences in cytokine gene expression profile between acute and secondary injury in adult rat spinal cord. Exp Neurol 184: 313-325, 2003.

7. Chan JK, Roth J, Oppenheim JJ, Tracey KJ, Vogl T, Feldmann M, Horwood $\mathrm{N}$ and Nanchahal J: Alarmins: Awaiting a clinical response. J Clin Invest 122: 2711-2719, 2012.

8. Pruenster M, Vogl T, Roth J and Sperandio M: S100A8/A9: From basic science to clinical application. Pharmacol Ther 167: 120-131, 2016.

9. Li Y, Chen B, Yang X, Zhang C, Jiao Y, Li P, Liu Y, Li Z, Qiao B, Bond Lau W, et al: S100a8/a9 signaling causes mitochondrial dysfunction and cardiomyocyte death in response to ischemic/reperfusion injury. Circulation 140: 751-764, 2019.

10. Marinković G, Grauen Larsen H, Yndigegn T, Szabo IA, Mares RG, de Camp L, Weiland M, Tomas L, Goncalves I, Nilsson J, et al: Inhibition of pro-inflammatory myeloid cell responses by short-term S100A9 blockade improves cardiac function after myocardial infarction. Eur Heart J 40: 2713-2723, 2019.

11. Zeng H, Liu N, Yang YY, Xing HY, Liu XX, Li F, La GY, Huang MJ and Zhou MW: Lentivirus-mediated downregulation of $\alpha$-synuclein reduces neuroinflammation and promotes functional recovery in rats with spinal cord injury. J Neuroinflammation 16: 283,2019

12. Zhao B, Lu R, Chen J, Xie M, Zhao X and Kong L: S100A9 blockade prevents lipopolysaccharide-induced lung injury via suppressing the NLRP3 pathway. Respir Res 22: 45, 2021.

13. Basso DM, Beattie MS and Bresnahan JC: A sensitive and reliable locomotor rating scale for open field testing in rats. J Neurotrauma 12: 1-21, 1995.

14. Bryan H, Timo N and Gemma P: The Cost Manual of Laboratory Animal Care and Use. USA: CRC Press, pp333-353, 2011.

15. Livak KJ and Schmittgen TD: Analysis of relative gene expression data using real-time quantitative PCR and the 2(-Delta Delta $\mathrm{C}(\mathrm{T})$ ) method. Methods 25: 402-408, 2001.

16. Wu Q, Wang Q, Li Z, Li X, Zang J, Wang Z, Xu C, Gong Y, Cheng J, Li H, et al: Human menstrual blood-derived stem cells promote functional recovery in a rat spinal cord hemisection model. Cell Death Dis 9: 882, 2018.

17. Kovačić M, Mitrović-Ajtić O, Beleslin-Čokić B, Djikić D, Subotički T, Diklić M, Leković D, Gotić M, Mossuz P and Čokić VP: TLR4 and RAGE conversely mediate pro-inflammatory S100A8/9-mediated inhibition of proliferation-linked signaling in myeloproliferative neoplasms. Cell Oncol (Dordr) 41: 541-553, 2018.

18. Lorey MB, Rossi K, Eklund KK, Nyman TA and Matikainen S: Global characterization of protein secretion from human macrophages following non-canonical caspase-4/5 inflammasome activation. Mol Cell Proteomics 16 (Suppl 1): S187-S199, 2017.

19. Ramer LM, Ramer MS and Bradbury EJ: Restoring function after spinal cord injury: Towards clinical translation of experimental strategies. Lancet Neurol 13: 1241-1256, 2014.

20. David S, López-Vales R and Wee Yong V: Harmful and beneficial effects of inflammation after spinal cord injury: Potential therapeutic implications. Handb Clin Neurol 109: 485-502, 2012.

21. Orr MB and Gensel JC: Spinal cord injury scarring and inflammation: Therapies targeting glial and inflammatory responses. Neurotherapeutics 15: 541-553, 2018.

22. Shah M, Peterson C, Yilmaz E, Halalmeh DR and Moisi M: Current advancements in the management of spinal cord injury: A comprehensive review of literature. Surg Neurol Int 11: 2, 2020.

23. Marino RJ, Ditunno JF Jr, Donovan WH and Maynard F Jr: Neurologic recovery after traumatic spinal cord injury: Data from the model spinal cord injury systems. Arch Phys Med Rehabil 80: 1391-1396, 1999.

24. Kirshblum S, Millis S, Mckinley W and Tulsky D: Late neurologic recovery after traumatic spinal cord injury. Arch Phys Med Rehabil 85: 1811-1817, 2004.

25. Enzmann G, Mysiorek C, Gorina R, Cheng YJ, Ghavampour S, Hannocks MJ, Prinz V, Dirnagl U, Endres M, Prinz M, et al: The neurovascular unit as a selective barrier to polymorphonuclear granulocyte $(\mathrm{PMN})$ infiltration into the brain after ischemic injury. Acta Neuropathol 125: 395-412, 2013.

26. Bao F, Chen Y, Schneider KA and Weaver LC: An integrin inhibiting molecule decreases oxidative damage and improves neurological function after spinal cord injury. Exp Neurol 214: 160-167, 2008. 
27. Nguyen HX, O'barr TJ and Anderson AJ: Polymorphonuclear leukocytes promote neurotoxicity through release of matrix metalloproteinases, reactive oxygen species, and TNF-alpha. J Neurochem 102: 900-912, 2007.

28. Nagareddy PR, Murphy AJ, Stirzaker RA, Hu Y, Yu S, Miller RG, Ramkhelawon B, Distel E, Westerterp M, Huang LS, et al: Hyperglycemia promotes myelopoiesis and impairs the resolution of atherosclerosis. Cell Metab 17: 695-708, 2013.

29. Cotoi OS, Dunér P, Ko N, Hedblad B, Nilsson J, Björkbacka H and Schiopu A: Plasma S100A8/A9 correlates with blood neutrophil counts, traditional risk factors, and cardiovascular disease in middle-aged healthy individuals. Arterioscler Thromb Vasc Biol 34: 202-210, 2014

30. Marinković G, Koenis DS, De Camp L, Jablonowski R, Graber N, de Waard V, de Vries CJ, Goncalves I, Nilsson J, Jovinge S and Schiopu A: S100A9 links inflammation and repair in myocardial infarction. Circ Res 127: 664-676, 2020.

31. Vogl T, Stratis A, Wixler V, Völler T, Thurainayagam S, Jorch SK, Zenker S, Dreiling A, Chakraborty D, Fröhling M, et al: Autoinhibitory regulation of S100A8/S100A9 alarmin activity locally restricts sterile inflammation. J Clin Invest 128: 1852-1866, 2018.
32. Lin XY, Lai BQ, Zeng X, Che MT, Ling EA, Wu W and Zeng YS: Cell transplantation and neuroengineering approach for spinal cord injury treatment: A summary of current laboratory findings and review of literature. Cell Transplant 25: 1425-1438, 2016

33. Li X, Xiao Z, Han J, Chen L, Xiao H, Ma F, Hou X, Li X, Sun J, Ding W, et al: Promotion of neuronal differentiation of neural progenitor cells by using EGFR antibody functionalized collagen scaffolds for spinal cord injury repair. Biomaterials 34 : 5107-5116, 2013.

34. De Filippo K, Dudeck A, Hasenberg M, Nye E, van Rooijen N, Hartmann K, Gunzer M, Roers A and Hogg N: Mast cell and macrophage chemokines CXCL1/CXCL2 control the early stage of neutrophil recruitment during tissue inflammation. Blood 121: 4930-4937, 2013

This work is licensed under a Creative Commons Attribution-NonCommercial-NoDerivatives 4.0 International (CC BY-NC-ND 4.0) License. 